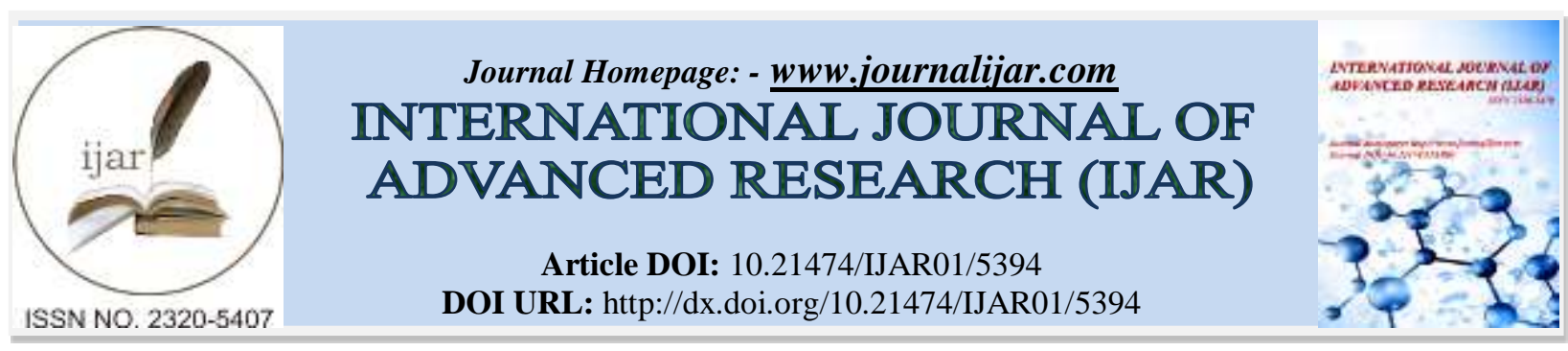

RESEARCH ARTICLE

\title{
NEURO-FUZZY MODEL FOR PREDICTION THE MECHANICAL PROPERTIES OF CARBON FIBER- EPOXY COMPOSITE.
}

\author{
Azhar D. Habeeb ${ }^{1}$, Dr Abdul Kareem F. Hassan ${ }^{1}$ and ${ }^{*}$ Dr Osama A. Abdullah ${ }^{2}$. \\ 1. Mechanical Department, Engendering College, Basra University. \\ 2. Marine College, Arabian Gulf Academy for Maritime Studies.
}

\section{Manuscript Info \\ Manuscript History \\ Received: 10 July 2017 \\ Final Accepted: 12 August 2017 \\ Published: September 2017}

Key words:-

Composite material, Fiber prestress,

Impact test, Neuro-fuzzy

\section{Abstract}

The aim of this work is to study the effect of fiber prestress on the impact strength and fracture toughness of carbon fiber-epoxy composite. A unidirectional laminates of $50 \%$ fiber volume fractions $(V f)$ were cured at ambient temperature, 55,80 , and $115^{\circ} \mathrm{C}$ under fiber prestressed by $0,10,20,30$, and $45 \mathrm{MPa}$. Specimens were cut according to ISO 179 for Charpy impact test. Neuro-fuzzy models were designed to predict the fracture toughness at different values of prestress level and curing temperature. The experimental results were accompanying with enhancing in the material toughness property, and they showed a good agreement with the predicted results.

Copy Right, IJAR, 2017,. All rights reserved.

\section{Introduction:-}

Various experimental investigations were carried out on the impact strength and fracture toughness of composite materials. S. Motahhari (1998), A. F. Hamzah et al. (2013), M. Karahan and N. Karahan (2014), Y.Sureshbabu and et al. (2014), M. Karahan and Nevin Karahan (2015) considered the influences of fiber prestressing, number of layers and fiber orientation, or hybridization on the impact strength of composite materials. They presented the effect on the toughness property in different manners.

Basically, fiber prestressing is utilized to minimize the induced residual stress and fiber waviness in the continuous fiber reinforced epoxy composite materials, and its influence on the material strength and stiffness was realized. While, most of the reinforced composites tend to behave as brittle materials, therefore, their brittleness and toughness properties are of major issues.

Numerical or theoretical methods, conventionally, were carried out to predict the mechanical properties and behaviours of materials, mainly for comparison matters. In this study, the experimental results of impact strength and fracture toughness are to be used to develop a neuro-fuzzy model to predict the desired properties.

\section{Composite Material:-}

The constituents are of carbon fiber and epoxy resin, all supplied by Sika International Company. The reinforcement is unidirectional carbon fibers PAN-based T300 as shown in figure1. This continuous fiber has a high strength of $3.9 \mathrm{GPa}$, and density of $1.79 \mathrm{~g} / \mathrm{cm}^{3}$. The matrix is a 2-part epoxy impregnation resin with tensile strength and density $30 \mathrm{MPa}$ and $1.31 \mathrm{~g} / \mathrm{cm}^{3}$ respectively, which was chosen according to the recommendation of the fibers product data sheet. 


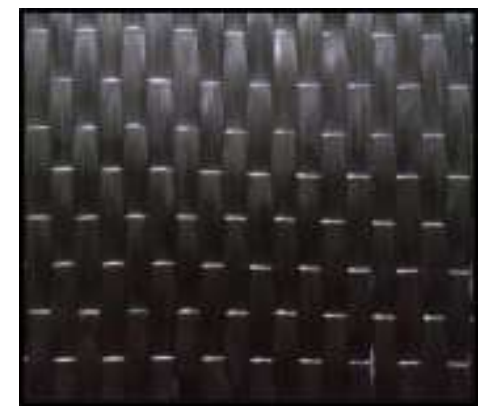

\section{Figure 1: Unidirectional woven carbon fiber fabric}

\section{Preparation of Carbon Fïber-Epoxy Composite:-}

The preparation of non-prestressed and prestressed composites was achieved by using Electric-Jack Prestress Rig (EJPR) methodology (see figure 2). The EJPR consists of three main parts; prestress assembly, pulling-jack, and low temperature furnace. Each part consists of several pieces and the whole parts are mounted on a structural frame. The prestress assembly of this machine has a surface of steel plate which can be used as an open moulding technique to produce thin flat strip for the impact test specimens.

Firstly, the surface of steel plate is cleaned and coated with a very thin layer of a free wax using a smooth cloth. Then a film of release agent called polyvinyl alcohol (PVA) is applied over the dried wax using a brush. The 50\% volume fraction epoxy is prepared by mixing the two substances with a mixing weight ratio of 1:4. The wetted laminas are to be fixed carefully, and gently rolled with the help of a teethed aluminium roller to remove any air or voids, as shown in figure 3.



Figure 2: The Electric Jack Prestress Rig (EJPR)

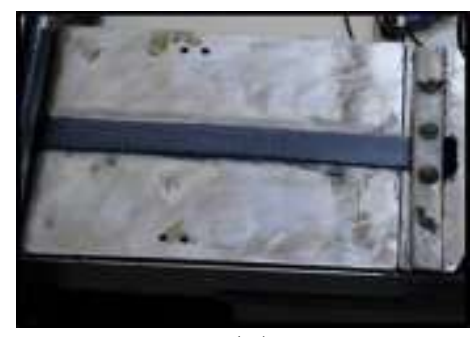

(a)

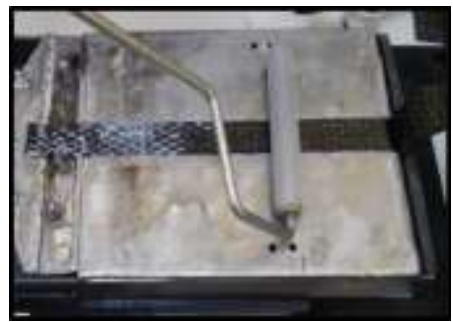

(b)

Figure 3: (a) Fixed carbon fiber laminas on the prestress assembly, and (b) Vacuum process by using teethed aluminium roller

The different prestress levels can be employed in the EJPR by applying mechanical loading to a predetermined level using load cell. Five different prestress levels $(0,10,20,30$ and $45 \mathrm{MPa})$ were applied at ambient temperature, $55,80,115^{\circ} \mathrm{C}$. The total applied prestress on the fibers is affected with the additional value of the mould thermal expansion and the induced residual stresses of the carbon fiber-epoxy composite. After eight hours of curing process, the furnace will be turned off and the laminate will be cooled down to ambient temperature. Usually 
normalizing takes about two hours, then the prestress assembly with the cured laminate will be drawn out from the furnace to remove the preloading gradually.

The laminates are removed from the mould, then cut and grinded to the suitable specimen's dimension according to the ISO 179-1:2000 standards. The cutting processes were done by using a small power angle grinder, and the entire test specimens were finished by abrading the edges on a fine abrasive paper to avoid any edge defects that could initiate premature failure.

\section{Charpy Impact Test}

A suitable Charpy impact test machine (see figure 4) has been used to determine the impact strength of materials according to ISO 179-1:2000. This standard is used also to investigate the behaviour of composites under the impact conditions for estimating the toughness of specimens. The dimension of the Charpy impact test specimens were $55 \times 10 \times 3.34 \mathrm{~mm}$ as illustrated in figure 5. The blow direction is to be at the flatwise-normal with respect to the specimen width or laminate plane. Five specimens were tested to measure the impact strength of each prestressed level (see Figure 6).


Figure 5: Flatwise-normal impact test
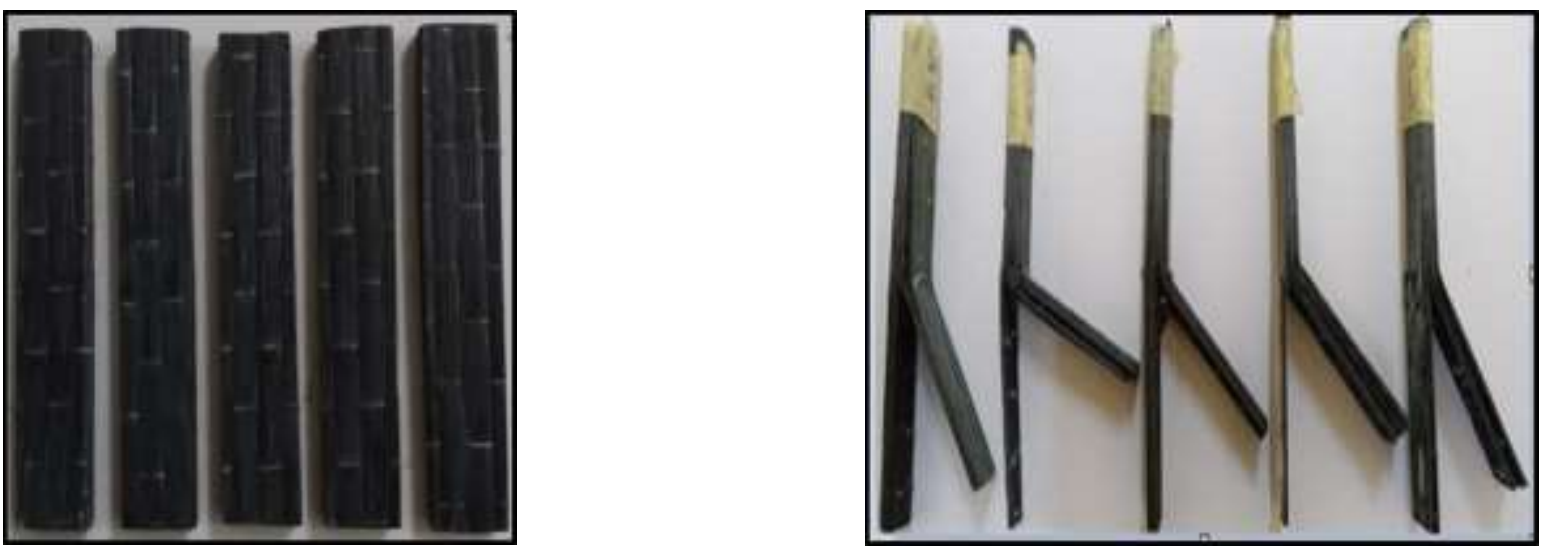

(a)

(b)

Figure 6: Charpy impact test specimens (a) before test and (b) after test
The calculation of the charpy impact strength of un-notched specimen depended on the calculation of the required energy for fracture, as follows:

$$
\mathrm{a}_{c U}=\frac{E_{S}}{h \cdot b} \times 10^{3}
$$

Where: $\mathrm{a}_{c U}$ is the charpy impact strength in $\left(\mathrm{KJ} / \mathrm{m}^{2}\right), E_{S}$ is the corrected energy absorbed by breaking the test specimen in $(\mathrm{J}), h$ is the thickness of the test specimen in $(\mathrm{mm})$ and $b$ is the width of the test specimen in (mm), as shown in figure 5 . 
Fracture toughness, which describes the ability of a material containing a crack, to resist fracture, can be expressed as:

$$
K_{c}=\sqrt{E \times \mathrm{a}_{c U}}
$$

Where: $K_{c}$ is the fracture toughness of composite material in (MPa. $\left.\sqrt{\mathrm{m}}\right)$ and $E$ is the elastic modulus of composite in $(\mathrm{GPa})$.

\section{Adaptive Neuro-Fuzzy Inference System (ANFIS):-}

The ANFIS is implemented for Takagi-Sugeno fuzzy rules. The ANFIS objects at systematically creating unknown fuzzy rules from a donated input-output data set. Though, ANFIS has a structured knowledge representation in the form of fuzzy "if-then" rules, therefore neural network learning understood have been integrated in fuzzy inference system, resulting in ANFIS. The ANFIS can be constructed as a five layer as shown in figure 7, with the following layer operations; Layer 1: generate fuzzy membership values for input variable, Layer 2: multiply the incoming signals from the previous layer and estimation the firing strength of each rule, Layer 3: compute the normalized firing strength, Layer 4: the node in this layer calculate the contribution of the (ith) rule in the model output based on first-order Takagi-Sugeno rules, and Layer 5: calculates the overal output as the summation of all incoming signals. In this model, mean square error (MSE) and correlation coefficient (R) are used to evaluate the prediction capability of ANFIS trained by each data set. The MSE and R can be defined as:

$$
\operatorname{MSE}=\frac{1}{N} \sum_{t=1}^{N}\left(A_{t}-F_{t}\right)^{2}
$$

Where $A_{t}$ and $F_{t}$ are actual and fitted values, respectively and $\mathrm{N}$ is the number of training or testing data set.

$$
\mathrm{R}=\frac{\sum_{t=1}^{N}\left(A_{t}-\bar{A}\right)\left(F_{t}-\bar{F}\right)}{\sqrt{\sum_{t=1}^{N}\left(A_{t}-\bar{A}\right)^{2} \cdot \sum_{t=1}^{N}\left(F_{t}-\bar{F}\right)^{2}}}
$$

Where $\bar{A}=\frac{1}{N} \sum_{t=1}^{N} A_{t}$, and $\bar{F}=\frac{1}{N} \sum_{t=1}^{N} F_{t}$ are the average values of $A_{t}$ and $F_{t}$ over the training or testing data.

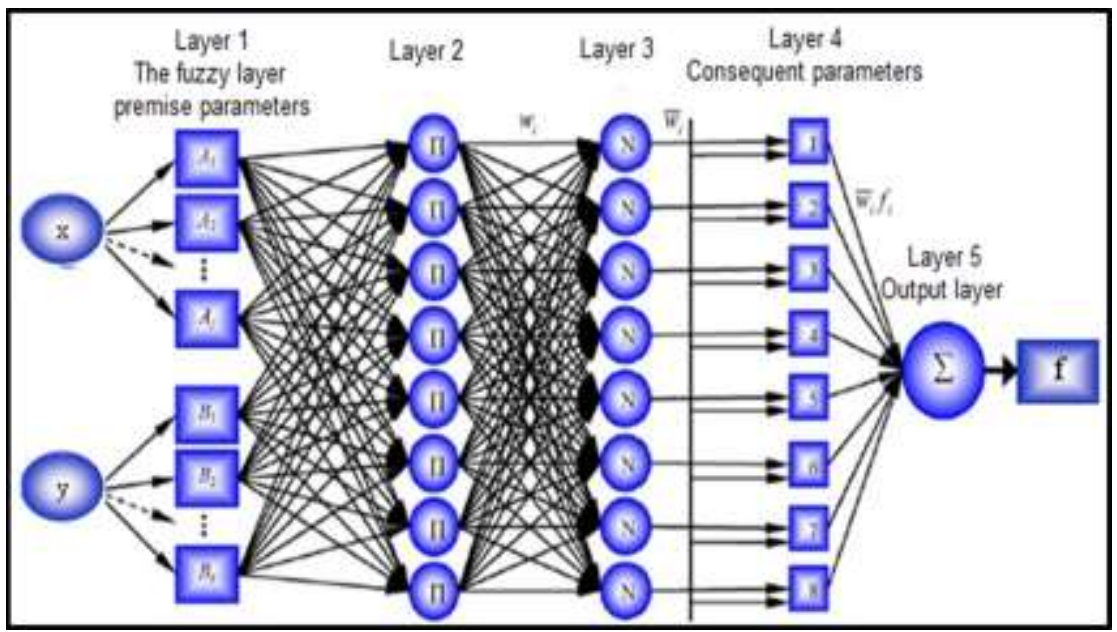

Figure 7: Adaptive Neuro-Fuzzy Inference System (ANFIS) structure. (Jyh-Shing 1997)

\section{Modelling of ANFIS for Carbon Fiber-Epoxy Composites :-}

A MATLAB package codes of ANFIS model was used to predict the impact strength and fracture toughness of carbon fiber-epoxy composite material. The effect of variation of the prestress level, and resin curing temperature on the output results is investigated. The numbers of testing and checking data are taken randomly, as $20 \%$ for testing and $20 \%$ for checking, approximately from the total experimental data and the rest for training.

The performance of ANFIS in these programming codes was investigated by changing several combinations such as; type of membership functions, numbers of membership functions and number of epochs. Where membership functions and numbers to input variable are appropriately fixed when testing data set has the highest correlation (R). 
After several attempts it was found that the best structure of the ANFIS for predicting the impact strength is two inputs in the first layer, six input membership functions in the second layer, twelve rules in third layer, twelve output membership functions in fourth layer and single output in fifth layer, as illustrated in figure 8-a. While, the best structure for predicting the fracture toughness is illustrated in figure 8-b.



(a)

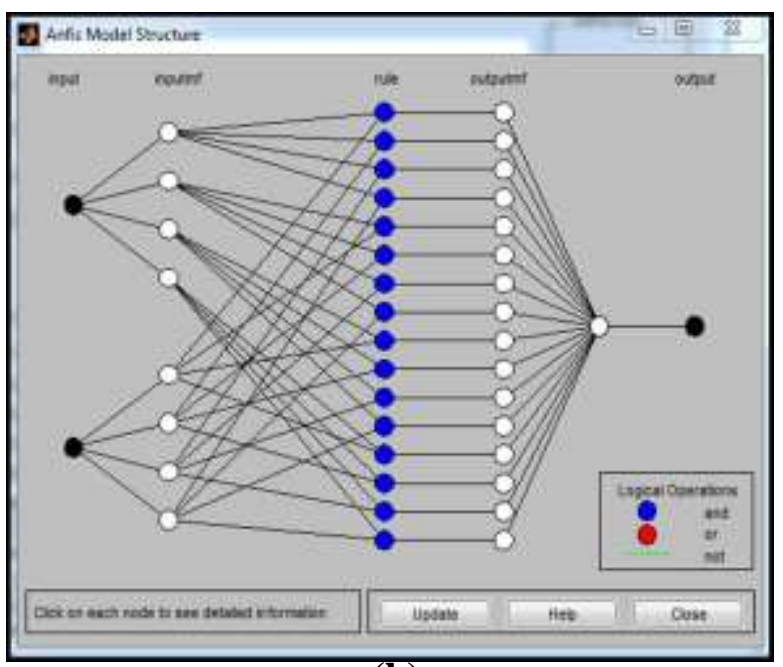

(b)

Figure 8: ANFIS structure of carbon fiber-epoxy composite properties. (a) 3-membership functions and (b) 4membership functions

It was observed that, Trapezoidal membership functions with 3 number of membership functions give the best performance for impact strength and, and Gaussian membership functions with 4 number of membership functions were used for fracture toughness as illustrated in Table 1. Whereas, a high correlation coefficient and mean square error of the best performance for predicting impact strength and fracture toughness are summarized. The best fit lines for prediction properties for training and testing specimens of this model are illustrated in figure 9.


(a) 

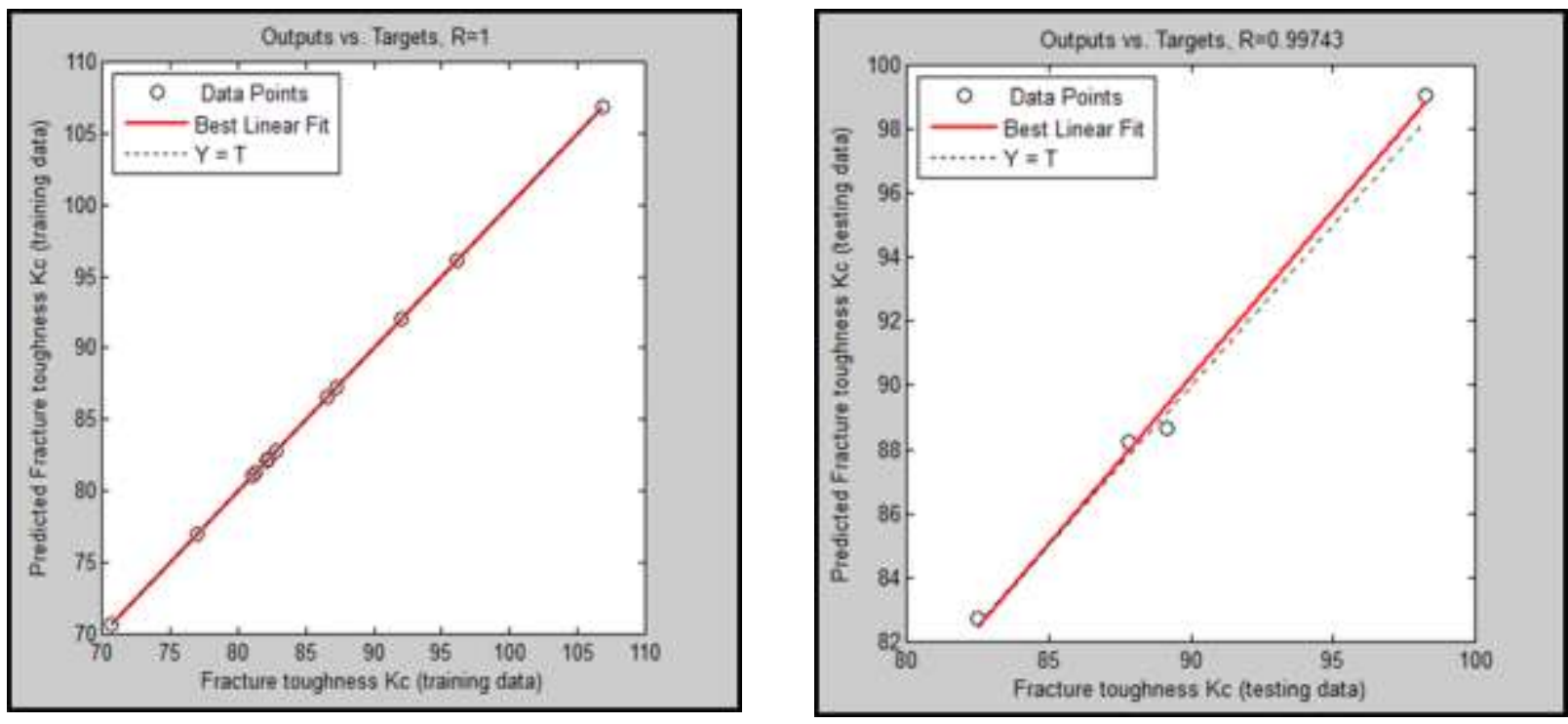

(b)

Figure 9: The best fit lines of the predicted values of carbon fiber-epoxy composite properties strength, and (b) for fracture toughness.

(a) for impact

Table (1) The best performance for predicting the mechanical properties of carbon fiber-epoxy composite material

\begin{tabular}{|c|c|c|c|c|c|c|c|}
\hline & & & & \multicolumn{2}{|c|}{ Training } & \multicolumn{2}{|c|}{ Testing } \\
\cline { 5 - 8 } $\begin{array}{c}\text { Output } \\
\text { parameter }\end{array}$ & $\begin{array}{c}\text { Type of } \\
\text { MFs }\end{array}$ & $\begin{array}{c}\text { No. of } \\
\text { MFs }\end{array}$ & $\begin{array}{c}\text { No. of } \\
\text { epoch }\end{array}$ & $\mathrm{R}$ & $\mathrm{MSE} \times 10^{-4}$ & $\mathrm{R}$ & $\mathrm{MSE}$ \\
\hline $\begin{array}{c}\text { Impact } \\
\text { strength }\end{array}$ & $\begin{array}{c}\text { Trapezo- } \\
\text { idal }\end{array}$ & 3 & 500 & 1.0000 & 0.000018 & 0.9992 & 0.5618 \\
\hline $\begin{array}{c}\text { Fracture } \\
\text { toughness }\end{array}$ & Gaussian & 4 & 500 & 1.0000 & 0.0000003 & 0.9974 & 0.2912 \\
\hline
\end{tabular}

\section{Results of Charpy Impact Test:-}

The effect of prestress level and curing temperature on the impact strength of the carbon fiber-epoxy composites is evident in figure 10. This figure shows the variation of the specimen's impact strength with the prestress level at ambient temperature, $55,80,115^{\circ} \mathrm{C}$, where the average impact strength value of every five specimens for each prestress level was plotted as a continuous line. Noting that, these samples were cured at ambient temperature to express the improvement of the impact strength as a function to the prestress level only.

It has been found that the average impact strength result at ambient temperature for non-prestress carbon fiber-epoxy specimen is $209.58 \mathrm{KJ} / \mathrm{m}^{2}$. Then, in figure 10 , there is a slight reduction from $209.58 \mathrm{KJ} / \mathrm{m}^{2}$ to $200.00 \mathrm{KJ} / \mathrm{m}^{2}$ in the composite impact strength when the carbon fibers prestress rises from zero to $10 \mathrm{MPa}$. This curve expresses a significant increment in the specimen's impact strength between the prestress levels 10 and 30MPa, until it reaches the value of $269.46 \mathrm{KJ} / \mathrm{m}^{2}$. Hence, the maximum percentage improvement of the specimen impact strength will be $28.571 \%$. Then any further preload on the fibers causes a reduction in the composite impact strength. It seems that this further preload will case a huge fiber retraction after releasing the load in the EJPR, which causes to damage in the interfacial bonding between fibers and epoxy, following by a reduction in the composite impact strength. It is found that the best prestress level of the carbon fibers when the epoxy cured at ambient temperature is $30 \mathrm{MPa}$. The results in figure 10 shows obviously that, all the impact strength values at $\left(55,80\right.$ and $\left.115^{\circ} \mathrm{C}\right)$ curing temperature are less than the strength values of that which cured at ambient temperature of the same prestress levels. The main reason of such reduction in the impact strength when heating the laminas is that the matrix was 
affected by the adjacent glass transition temperature, and the shear strength of the interfacial bonding are reduced inversely with raising curing temperature.

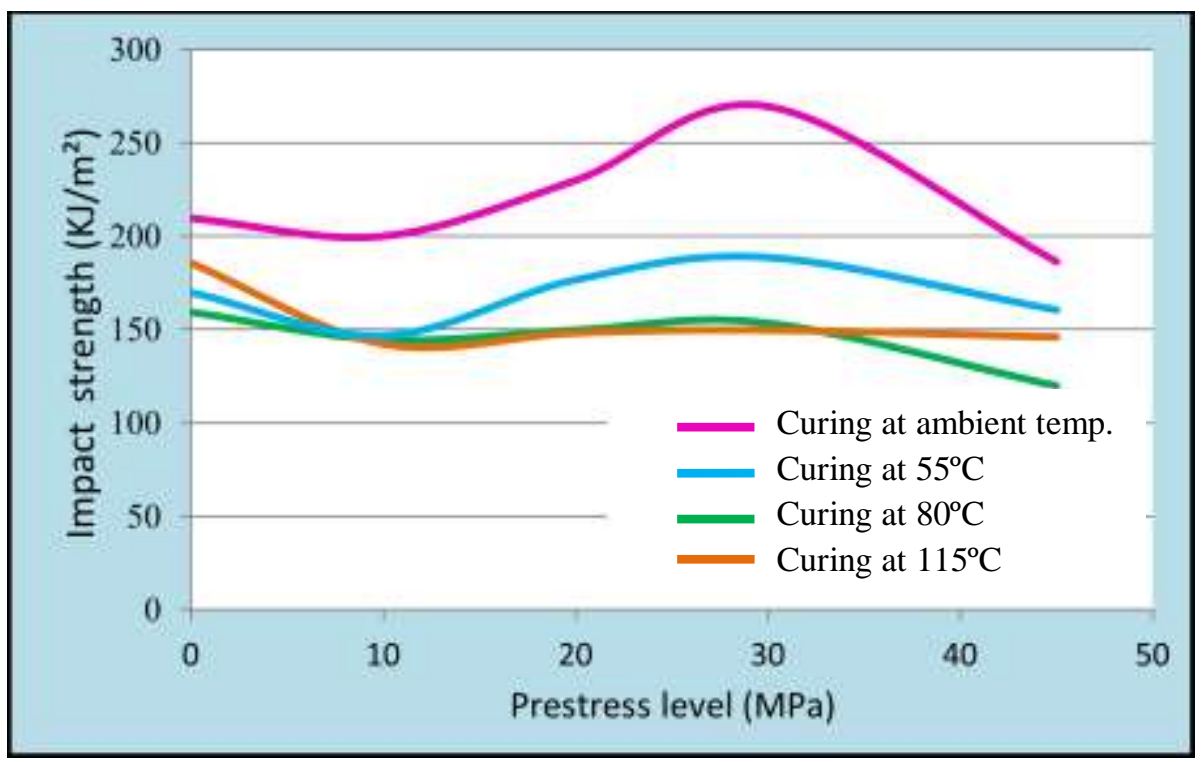

Figure 10: Average impact strength for carbon fiber-epoxy composites at different curing temperature versus prestress level

For fracture toughness of the carbon fiber-epoxy composite was calculated from equation (2), where the modulus of elasticity of the carbon fiber-epoxy composites at ambient temperature was taken from accurate previous studies. The rest modulus of elasticity was calculated using the slope of the linear part of the stress-strain curve in tensile test. The results of fracture toughness are plotted as a function of fiber prestress level as shown in figure 11. In this figure the curve expresses continuous increment in the specimen's fracture toughness between the non-prestress levels and $30 \mathrm{MPa}$ at ambient temperature, 55 and $80^{\circ} \mathrm{C}$, where it reached the value of $106.888 \mathrm{MPa} . \sqrt{\mathrm{m}}$ at ambient temperature. The maximum percentage improvement of the specimen fracture toughness between the nonprestressed composite and prestress composite at $30 \mathrm{MPa}$ is $29.914 \%$ at ambient temperature. While, at $115^{\circ} \mathrm{C}$ the increment in the specimen's fracture toughness was between the non-prestress levels and $20 \mathrm{MPa}$. This increment can be attributed to the increase in the modulus of elasticity and impact strength of the composite due to the carbon fibers retraction. While, the declination in the curve later is happen due to the interfacial debonding. Also, it is observed that, as the temperature increases, the fracture toughness decreases in carbon fiber-epoxy composite materials due to decreases the impact strength with increases temperature. 


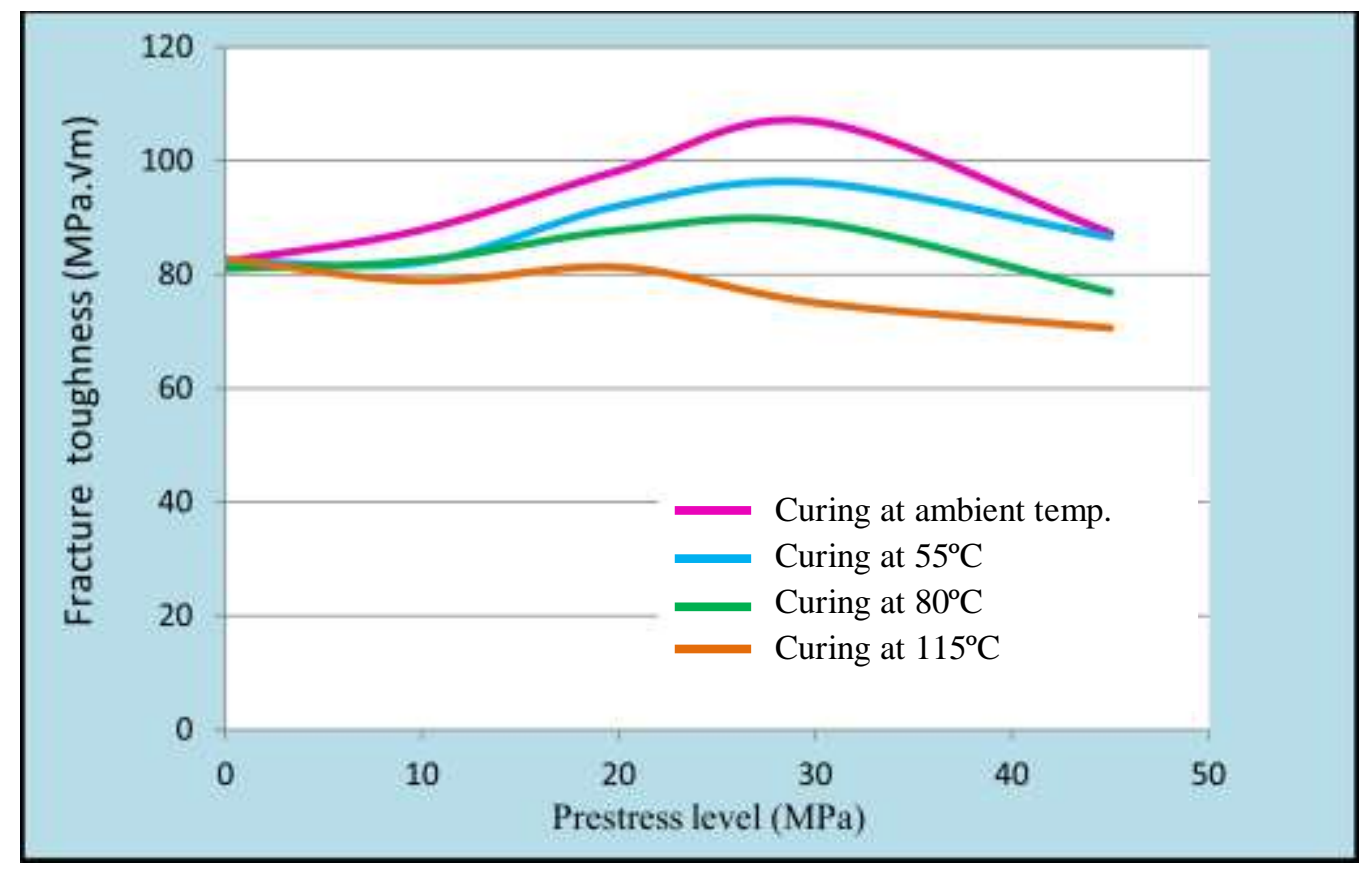

Figure 11: Fracture toughness for carbon fiber-epoxy composites at different curing temperature versus prestress level

\section{Results of Neuro-Fuzzy Model}

The neuro-fuzzy developed with two input parameters; prestress level and curing temperature and one output; impact strength or fracture toughness. From results, it was found that, Trapezoidal membership functions with 3membership functions gave the best performance for impact strength. The Gaussian membership functions with 4membership functions were used for predicting the fracture toughness, as shown in second row of table 1. From this table, it can be noted that a high correlation coefficients and less mean square errors were achieved in predicting the impact strength and fracture toughness.

Table 2 exhibits the experimental and predicted neuro-fuzzy results with their percentage error. It is clear that the mean error between the experimental and predicted neuro-fuzzy is $0.456 \%$ and $0.541 \%$ for impact strength and fracture toughness respectively. It can be seen the predictions of this model shows a good agreement with experimental values.

Table 2: Comparison between the experimental and predicted neuro-fuzzy results of carbon fiber-epoxy composite properties

\begin{tabular}{|c|c|c|c|c|c|}
\hline \multicolumn{3}{|c|}{ Impact strength $\left(\mathrm{KJ} / \mathrm{m}^{2}\right)$} & \multicolumn{3}{c|}{ Fracture toughness $(\mathrm{MPa} . \sqrt{\mathrm{m}})$} \\
\hline Exp. & $\begin{array}{c}\text { Neuro- } \\
\text { Fuzzy }\end{array}$ & Error\% & Exp. & $\begin{array}{c}\text { Neuro- } \\
\text { Fuzzy }\end{array}$ & Error\% \\
\hline 144.46 & 145.29 & 0.575 & 82.49 & 82.71 & 0.267 \\
\hline 176.65 & 175.67 & 0.555 & 98.27 & 99.10 & 0.845 \\
\hline 148.20 & 147.82 & 0.256 & 87.80 & 88.23 & 0.489 \\
\hline 153.44 & 154.11 & 0.437 & 89.15 & 88.65 & 0.561 \\
\hline \multicolumn{2}{|c|}{ Mean error \% } & 0.456 & \multicolumn{2}{|c|}{ Mean error \% } & 0.541 \\
\hline
\end{tabular}

\section{Conclusion:-}

It was noted that the fiber prestress and curing processes under high temperatures (less than glass transition temperature) were much helpful in improving impact strength and fracture toughness of the carbon fiber-epoxy 
composite. They were improved as much as $28.571 \%$ and $29.914 \%$ respectively. In general and with respect to the fiber volume fraction, the best prestress level for carbon fiber-epoxy composite is limited at $30 \mathrm{MPa}$, and the best curing temperature is ambient temperature. Neuro-Fuzzy model was used successfully in this work to support the reasonability of the experimental results.

\section{References:-}

1. Ahmed F. Hamzah, Prof. Dr.Najim A .Saad and Assist. Prof. Dr.Mohammed S. Hamzah, "Experimental and Numerical Simulation of Impact Fracture Toughness of Polyphenylene Sulfide Basis Composite Material", The Second International Scientific Conference of College of Materials Engineering-University of Babylon, 2013.

2. ISO 179-1:2000. Plastics-Determination of Charpy impact properties. International Standard ISO 179-1 as a European Standard, 2000.

3. I. O. Bachi, N. Abdulr azzaq and Zeng He, "Neuro Fuzzy Model for predicting the Dynamic Characteristics of Beams", Acta Mechanica Solida Sinica, Vol. 27, No. 1, 2014,pp. 85-96.

4. Jyh-Shing Roger Jang, Chuen-Tsai and Eiji Mizutani,"Neuro-Fuzzy and soft computing: A computational Approach to Learning and Machine Intelligence", Tsing Hua University,3rd Edition, ISBN: 0-13-2610663,1997.

5. Katarina Uusitalo, "Designing in Carbon Fiber Composites", M.S.C. Thesis, Chalmers University of Technology, 2013.

6. Mehmet Karahan and Nevin Karahan," Effect of Weaving Structure and Hybridization on the Low-Velocity Impact Behavior of Woven Carbon-Epoxy Composites", Fibres \& Textiles in Eastern Europe, Vol. 22, 3(105), 2014,pp. 109-115.

7. Mehmet Karahan and Nevin Karahan, "Investigation of The Tensile Properties of Natural And Natural/Synthetic Hybrid Fiber Woven Fabric Composites", Journal of Reinforced Plastics and Composites 0 (0), 2015,pp. 1-12.

8. Osama Abdul Aziz Abdullah, "Effect of Fiber Prestress and Curing Temperature on the Tensile and Flexural Properties of Carbon Fiber-Epoxy Composite", PhD thesis, University of Basrah, 2016.

9. Siamak Motahhari, "A study of The Influences of Fiber Prestressing on The Mechanical Properties of Polymer Matrix Composites", PhD thesis, Queen's University Kingston, Ontario, Canada, 1998.

10. Sika Gulf B.S.C., Sikadur®-330 Product Data Sheet, Edited by Bldg. 925, Kingdom of Bahrain, 2006.

11. Sika Kimia Sdn Bhd, SikaWrap®-300 C Product Data Sheet, Edited by Lot 689 Nilai Industrial Estate, Malaysia, 2010.

12. S. A. Bakar, R. M. Dom, A. B. Akbarally, and W. H. Wan Hassan, "Role of Input Selection Prediction of Physical Properties of Degradable Composites Using ANFIS", International Journal of Materials, Mechanics and Manufacturing, Vol. 3, No. 3, 2015,pp. 213-217.

13. Y.Sureshbabu, C.Naresh and S.Bhargavi Devi, "Experimental Test on Carbon Fiber/Epoxy and Glass Fiber/Epoxy Pultruded Rods for Mechanical Properties", International Journal of Engineering Research, Volume No.3, Issue No: Special 1, 2014,pp. 135-139. 